\title{
Trimethoprim, Creatinine and Creatinine-Based Equations
}

\author{
Pierre Delanaye $^{\mathrm{a}}$ Christophe Mariat $^{\mathrm{b}}$ Etienne Cavalier ${ }^{\mathrm{c}}$ Nicolas Maillard ${ }^{\mathrm{b}}$ \\ Jean-Marie Krzesinski ${ }^{a}$ Christine A. White ${ }^{d}$ \\ a Department of Nephrology, Dialysis, Hypertension, Transplantation, University of Liège, Liège, Belgium; \\ ${ }^{b}$ Department of Nephrology, Dialysis, Hypertension, Transplantation, Hôpital Nord, Jean Monnet University, \\ Saint-Etienne, France; ${ }^{c}$ Department of Clinical Chemistry, CHU Sart Tilman, University of Liège, Liège, Belgium; \\ ${ }^{\mathrm{d} D i v i s i o n}$ of Nephrology, Department of Medicine, Queen's University, Kingstone, Ont., Canada
}

\section{Key Words}

Trimethoprim $\cdot$ Creatinine $\cdot$ Glomerular filtration rate

\begin{abstract}
Co-trimoxazole is a frequently prescribed antibiotic worldwide. It is composed of both trimethoprim and sulfamethoxazol (Sfx) and is used in the treatment and prophylaxis of urinary tract and Pneumocystis jirovecii infections. The Sfx component appears to be nephrotoxic at high doses or doses inappropriately adjusted for glomerular filtration rate (GFR). The trimethoprim component, even at recommended doses, inhibits tubular creatinine secretion, leading to a rapid but ultimately reversible increase in serum creatinine independent of any changes in GFR. This translates into a falsely low estimated GFR when creatinine-based equations are used. This review focuses on evidence of the differential effects of trimethoprim and Sfx on serum creatinine concentrations and GFR and their relevance to clinical practice, with particular attention to kidney transplantation.
\end{abstract}

Copyright $\odot 2011$ S. Karger AG, Basel

\section{Introduction}

Trimethoprim, generally combined with sulfamethoxazol (Sfx), is one of the most frequently prescribed antibiotics in nephrology. This combinations, also known as co-trimoxazole, is indicated for the preventive or curative treatment of urinary infections (in all populations) and of Pneumocystis jirovecii infections (in HIV+ and transplanted patients) [1-3]. Trimethoprim was fully described for the first time in 1962 [4] and has been available in Europe since 1968 in combination with Sfx. Co-trimoxazole is rapidly and efficiently absorbed after oral administration. Peak serum concentrations are observed in the first $4 \mathrm{~h}[2,5] ; 66 \%$ of Sfx and $45 \%$ of trimethoprim are bound to protein [2], $10-30 \%$ of trimethoprim and $20 \%$ of Sfx are metabolized, and the metabolites are inactive [6]. The parent compounds are excreted in the urine and bile. In individuals with normal renal function, the plasma halflives of trimethoprim and Sfx are 11 and $9 \mathrm{~h}$, respectively [7]. If the creatinine clearance is below $15-30 \mathrm{ml} / \mathrm{min}$, it is recommended to decrease the total dose per $24 \mathrm{~h}$ by half $[2,8]$. In 1968, Hanley [9] suspected a causal role of cotrimoxazole in 4 cases of oliguria that occurred within the first 6 months after commercialization of co-trimoxazole. However, the potential nephrotoxicity of trimethoprim and/or Sfx has been questioned [10]. 


\section{Are Trimethoprim and/or Sfx Nephrotoxic? The First Cases}

The first article on this specific topic was published in 1973 by Kalowski et al. [11], who retrospectively described 16 cases of acute renal failure who had been treated with high-dose co-trimoxazole ( 800 or 1,600 $\mathrm{mg} \mathrm{Sfx}$ and 80 $\mathrm{mg}$ trimethoprim per day). Fourteen of these patients had preexisting chronic kidney disease (CKD), defined as serum creatinine $>1.5 \mathrm{mg} / \mathrm{dl}$. Overall, serum creatinine increased from $3.0 \pm 0.56$ to $5.6 \pm 0.92 \mathrm{mg} / \mathrm{dl}$ and creatinine clearance decreased from 40 to $16 \mathrm{ml} / \mathrm{min}$. In $3 \mathrm{pa}-$ tients, serum creatinine did not return to baseline after cessation of therapy. Renal biopsies were performed in 2 patients and showed acute tubular necrosis [11]. Subsequently, others have reported cases of biopsy-proven tubulointerstitial nephrotoxicity, with high doses of co-trimoxazole occurring mainly, but not exclusively, in patients with CKD [12-20]. Since tubulointerstitial nephritis has also been described with other sulfonamides in monotherapy [11,21], Kalowski et al. [11] hypothesized that co-trimoxazole nephrotoxicity was probably related to Sfx rather than to trimethoprim. Several authors have subsequently shown that renal safety seems to be excellent if appropriate dose adjustments are made for impaired renal function [22, 23]. In 1975, Tasker et al. [22] prospectively followed $20 \mathrm{CKD}$ patients (mean serum creatinine: $4.47 \mathrm{mg} / \mathrm{dl}$ ) with urinary or respiratory infection treated with co-trimoxazole. Three patients suffered from a nonreversible deterioration of their renal function, which was attributed to sepsis-related acute renal failure and acute tubular necrosis rather than to co-trimoxazole $[22,24]$. Although the authors state that the remaining 17 patients did not experience any significant change in serum creatinine [22], a review of the data presented reveals that 11 experienced a rise in serum creatinine of $0.2-0.8 \mathrm{mg} / \mathrm{dl}$ during the treatment $[13,22]$. This was, however, reversible in most patients, and serum creatinine returned to baseline after therapy cessation.

\section{Trimethoprim-Induced Serum Creatinine Elevation: The Evidence}

In 1975, Berglund et al. [25] published the first important study illustrating the effect of trimethoprim on serum creatinine. They described an increase in serum creatinine in 21 sequential subjects (mean serum creatinine: $0.85 \pm 0.18 \mathrm{mg} / \mathrm{dl}$, range: 0.6 to $1.4 \mathrm{mg} / \mathrm{dl}$ ) treated with co-trimoxazole at a dose of $1,600 \mathrm{mg} \mathrm{Sfx}$ and $160 \mathrm{mg}$ tri- methoprim per day for 12 days. During treatment, serum creatinine increased by an average of $0.22 \mathrm{mg} / \mathrm{dl}$ or $20 \%$, with increases ranging from 0 to $0.4 \mathrm{mg} / \mathrm{dl}$. Only 1 subject had a stable serum creatinine. The increase in serum creatinine was higher in individuals with higher baseline serum creatinine concentrations. All serum creatinine concentrations returned to baseline within 5 days after treatment termination. Importantly, Berglund et al. excluded any type of analytical interferences. The addition of increasing concentrations of co-trimoxazole to plasma did not modify serum creatinine measurement by the method of Jaffé. Although initially questioned [26], the absence of analytical interference was later confirmed by 3 other authors [27-29]. Berglund et al. [25] also measured the creatinine clearance and glomerular filtration rate (GFR) by a reference method (iothalamate) in 4 healthy subjects before, during and after co-trimoxazole therapy. They described, for the first time ever, an increase in serum creatinine with a concomitant fall in creatinine clearance and no significant change in GFR. This suggested that the observed increase in creatinine was due to inhibition of tubular creatinine secretion rather than a result of a decline in GFR [25]. In the same article, Berglund et al. also showed that the effect of co-trimoxazole on creatinine begins as early as $2 \mathrm{~h}$ after intake and reaches a maximal peak within 4-6 h. Berglund et al. did not study the duration of the inhibition induced by co-trimoxazole, but, based on previous pharmacological studies, they suggested that this effect could last for at least $24 \mathrm{~h}[1,25,30]$. The final observation in the article by Berglund et al. is interesting as well. After studying the effect of monotherapy with trimethoprim and Sfx in 2 subjects, they concluded that the inhibition of tubular creatinine secretion was likely to be exclusively linked to trimethoprim rather than to Sfx. There are several limitations to the study by Berglund et al. The sample size was small and no CKD patients were included. Moreover, creatinine clearance was lower than GFR in 2 subjects, which is difficult to understand given tubular creatinine secretion. Lastly, the inhibition of tubular creatinine secretion seems high (mean decrease in creatinine secretion of $25 \%$ ) in these healthy subjects [31].

In 1975, Caterson et al. [24] published another a priori interesting study. They studied 22 stable renal transplant recipients and measured GFR (inulin) before and after trimethoprim. Unlike Berglund et al. [25], they reported no significant changes in either GFR or creatinine clearance. However, these data are limited by a delay of $36 \mathrm{~h}$ between therapy cessation and GFR measurement. It was not until the eighties that a convincing confirmation of the hypoth- 
esis of Berglund et al. [25] was published. Trollfors et al. [32] measured GFR $\left({ }^{51} \mathrm{Cr}\right.$-EDTA clearance) in a heterogeneous group of 25 patients (GFR ranging from 13 to 160 $\mathrm{ml} / \mathrm{min}$ ) before and during co-trimoxazole therapy (2.2$7.1 \mathrm{mg} / \mathrm{kg} /$ day for 7-19 days). GFR remained stable in 21 patients while serum creatinine increased from $1.32 \pm$ 0.98 to $1.45 \pm 1.11 \mathrm{mg} / \mathrm{dl}$ and creatinine clearance decreased from $73 \pm 34$ to $63 \pm 32 \mathrm{ml} / \mathrm{min}$. The results of this study are somewhat difficult to interpret because of the heterogeneity in patients' GFR and co-trimoxazole dosage. Moreover, all patients were infected and cannot be considered as 'stable'. Lastly, the baseline GFR measurement was performed after therapy had begun in 9 subjects. Two of the CKD patients experienced a GFR decline that was attributed to nephrotoxicity from high doses of co-trimoxazole that were not adjusted for their decreased renal function. Two other patients also experienced a decrease of their GFR that was attributed to sepsis and acute pyelonephritis [32]. In 1981, Kainer and Rosenberg [33] studied the effect of co-trimoxazole $(30 \mathrm{mg} / \mathrm{kg}$ of Sfx and $6 \mathrm{mg} / \mathrm{kg}$ of trimethoprim) in 10 young healthy subjects. Serum creatinine, creatinine clearance and GFR $\left({ }^{51} \mathrm{Cr}\right.$-EDTA $)$ were measured before, on the $3 \mathrm{rd}$ and $7 \mathrm{th}$ day of therapy and 1 week after treatment cessation. During therapy, serum creatinine significantly increased by $16.5 \%$ on the 3 rd day and by $17.6 \%$ on the 7 th day, while creatinine clearance decreased by 26.3 and $21.2 \%$ on the $3 \mathrm{rd}$ and 7 th day, respectively. All measurements returned to their original concentrations after the end of treatment. GFR remained unchanged throughout the course of therapy [33]. In 1985, Kastrup et al. [27] studied trimethoprim alone. Fifteen healthy subjects were treated with $200 \mathrm{mg}$ trimethoprim for 14 days. GFR $\left({ }^{51} \mathrm{Cr}-\mathrm{EDTA}\right)$ and creatinine clearance were measured before and after therapy in 6 subjects. Serum creatinine increased in all subjects. In the 6 patients in whom GFR was measured, serum creatinine increased by $23 \%$, creatinine clearance decreased by $22 \%$ and GFR was unchanged [27]. In 1989, Berg et al. [28] examined the effects of co-trimoxazole therapy in renal transplant recipients. At that time, several authors had suggested that concomitant therapy with co-trimoxazole and cyclosporine could potentiate nephrotoxicity. This was based on retrospective data obtained from transplant recipients suffering from urinary or $P$. jirovecii infections and who were thus prone to sepsis-associated acute tubular necrosis [18, 34-36]. Berg et al. included 16 stable, noninfected renal transplant recipients. Eight were treated with cyclosporine. Their serum creatinine was below 2.04 $\mathrm{mg} / \mathrm{dl}$ and their mean GFR ( $\left.{ }^{99} \mathrm{Tc}-\mathrm{DTPA}\right)$ was $56 \mathrm{ml} / \mathrm{min}$. The other 8 patients were treated with azathioprine and had serum creatinine concentrations below $1.81 \mathrm{mg} / \mathrm{dl}$ and mean GFRs of $74 \mathrm{ml} / \mathrm{min}$. Trimethoprim was prescribed at $320 \mathrm{mg}$ for 7 days. Creatinine, creatinine clearance and GFR were measured before and after therapy. A similar increase in serum creatinine concentration was observed in both groups ( $+28 \%$ in the cyclosporine group and $+29 \%$ in the azathioprine group). A decrease in creatinine clearance in both groups was also seen although this was more impressive in the cyclosporine group (24 vs. 9\%). Once again, GFR remained unchanged in all patients. Serum creatinine returned to baseline concentrations 1 week after treatment cessation in all patients [28]. In 1992, Maki et al. [29] also studied cyclosporine-treated renal transplant recipients. Using a cross-over design, 17 stable, noninfected transplant recipients were alternately treated with prophylactic doses of co-trimoxazole $(800$ $\mathrm{mg}$ Sfx and $160 \mathrm{mg}$ trimethoprim) and placebo. GFR was identical in the two groups and remained unchanged throughout the study. During both treatment periods, the co-trimoxazole group had a higher mean serum creatinine and a lower mean creatinine clearance than the placebo group. Thus, in both of the above studies, no specific deleterious renal effects were observed with the combination of cyclosporine and co-trimoxazole. Together, the above trials summarized in table 1 support the hypothesis originally proposed by Berglund et al. [25] that trimethoprim inhibits tubular creatinine secretion [25, $27-29,32,33$. Trimethoprim is a cationic drug and its effect on tubular creatinine secretion is similar to that of cimetidine [37]. Both act as inhibitors of organic cation transport via which creatinine is secreted in the distal tubule $[28,38-40]$. This has been well documented in both cell cultures and animal studies [38]. From a theoretical point of view, creatinine clearance measured in patients treated with trimethoprim would be a better estimator of GFR than creatinine clearance in patients not on trimethoprim. This has been documented with cimetidine, another inhibitor of creatinine [41].

The magnitude of tubular creatinine secretion inhibition induced by trimethoprim has been explored by a number of groups [30, 42-46]. Dijkmans et al. [42] found a $15-20 \%$ increase in serum creatinine in renal transplant recipients with urinary tract infections. Furthermore, the elevation was more pronounced in those with higher initial creatinine concentrations and the degree of elevation correlated with plasma trimethoprim concentrations (but not with Sfx concentrations). Roy et al. [45] treated 10 healthy subjects with co-trimoxazole $(1,600 \mathrm{mg} \mathrm{Sfx}$ and $160 \mathrm{mg}$ trimethoprim) for 1 week followed by Sfx alone for 1 week after a 1-week washout period. Creati- 
Table 1. Trials having studied the trimethoprim effect on serum creatinine using a reference method for GFR measurement

\begin{tabular}{|c|c|c|c|}
\hline References & Sample and dosage & $\begin{array}{l}\text { Serum } \\
\text { creatinine, } \mathrm{mg} / \mathrm{dl}\end{array}$ & $\begin{array}{l}\text { Increase in } \\
\text { serum creatinine }\end{array}$ \\
\hline Berglund et al. [25] & $\begin{array}{l}21 \text { infected patients } \\
\text { Ctx }(2 \times 800 \mathrm{mg} \mathrm{Sfx}+160 \mathrm{mg} \text { Tmp })\end{array}$ & $\begin{array}{l}0.6-1.4 \\
0.85 \pm 0.18\end{array}$ & $0.22 \mathrm{mg} / \mathrm{dl}(+20 \%)$ \\
\hline Trollfors et al. [32] & $\begin{array}{l}25 \text { infected patients } \\
\text { Ctx }(2.2-6.5 \mathrm{mg} / \mathrm{kg} / \text { day })\end{array}$ & $1.32 \pm 0.98$ & $0.13 \mathrm{mg} / \mathrm{dl}(+10 \%)$ \\
\hline Kainer and Rosenberg [33] & $\begin{array}{l}10 \text { healthy subjects } \\
\text { Ctx }(30 \mathrm{mg} / \mathrm{kg} / \text { day } \mathrm{Sfx}+6 \mathrm{mg} / \mathrm{kg} / \text { day Tmp })\end{array}$ & normal range & $+17 \%$ \\
\hline Kastrup et al. [27] & $\begin{array}{l}15 \text { healthy subjects } \\
\text { Tmp ( } 200 \mathrm{mg} \text { /day) }\end{array}$ & normal range & $+23 \%$ \\
\hline Berg et al. [28] & $\begin{array}{l}16 \text { stable renal transplant recipients } \\
\text { Tmp }(2 \times 160 \mathrm{mg})\end{array}$ & $<2.04$ & $+28 \%$ \\
\hline
\end{tabular}

Conversion factors: serum creatinine in milligrams per deciliter to micromoles per liter: $\times 88.4$. Tmp $=$ Trimethoprim; Ctx $=$ co-trimoxazole.

nine increased by $13 \%$ only after co-trimoxazole, further confirming that inhibition of tubular creatinine secretion is unique to trimethoprim. Sandberg and Trollfors [46] documented a $23 \%$ increase in serum creatinine in 14 non-CKD patients with uncomplicated acute cystitis treated with trimethoprim ( $320 \mathrm{mg} /$ day for 7 days). Myre et al. [43] studied 10 noninfected healthy subjects and 9 stable noninfected CKD patients (mean serum creatinine: $3.66 \pm 0.24 \mathrm{mg} / \mathrm{dl})$ treated with trimethoprim $(200$ $\mathrm{mg}$ ) for 10 days. Serum creatinine reversibly increased by $14.8 \%$ in the healthy subjects as compared to $34.6 \%$ in the CKD patients. Odutola et al. [47] showed a decrease in mean serum creatinine from $1.82 \pm 0.66$ to $1.63 \pm 0.59$ $\mathrm{mg} / \mathrm{dl}$ in 100 renal transplant recipients after cessation of co-trimoxazole therapy (800 $\mathrm{mg} \mathrm{Sfx}$ and $80 \mathrm{mg}$ trimethoprim). The higher the initial creatinine concentration, the greater the proportional decrease. Naderer et al. [44] compared the differential effect of two different dosages of trimethoprim on serum creatinine in 20 healthy subjects. With the classical antibacterial dosage $(10 \mathrm{mg} / \mathrm{kg} /$ day), serum creatinine increased by $26 \%(0.2 \pm 0.13 \mathrm{mg} /$ dl) as compared to $31 \%(0.28 \pm 0.18 \mathrm{mg} / \mathrm{dl})$ with the higher dosage recommended for $P$. jirovecii infections (20 $\mathrm{mg} / \mathrm{kg} /$ day). These differences did not reach statistical significance, however.

In all studies, serum creatinine reverted to baseline after cessation of therapy. However, the effect can last as a function of the drug half-life, which ranges from 11 to $17 \mathrm{~h})[1,2,25,30]$ depending on the GFR. In CKD patients, the drug half-life may be doubled or tripled $[1,48]$.

\section{Trimethoprim-Induced Serum Creatinine Elevation: Conclusions}

Trimethoprim induces a reversible and rapid (2-6 h after intake) $[25,30]$ increase in serum creatinine and a decrease in creatinine clearance. These occur independently of changes in GFR and are mediated through inhibition of tubular creatinine secretion [27-29, 32, 33, 49, 50]. In healthy subjects, the increase in serum creatinine ranges between $13 \%[33,43,46]$ and $23 \%[25,27,32,45]$. The observed variation is likely due to differing dosages although this has not been definitely proven [44]. The lowest dose of trimethoprim studied to date is $160 \mathrm{mg} /$ day and it is not known whether lower doses have the same effect on serum creatinine concentration [29]. In patients with CKD, the increase in serum creatinine concentration is more pronounced than in healthy subjects and has been described to be higher than $35 \%[25,28,42$, 43], which is not unexpected given the known increase in creatinine secretion as GFR declines. Studies to date reveal that trimethoprim possesses minimal if any true nephrotoxicity. To the best of our knowledge, no convincing cases of acute renal failure have been described with this drug in monotherapy at a prophylactic dosage. A single patient treated with trimethoprim who developed acute kidney injury has been reported, but this is confounded by the concurrent use of a nonsteroidal anti-inflammatory drug [51]. It is clear that the combination of trimethoprim and Sfx can induce acute renal failure, especially if the dosage is not appropriately adjusted to renal 
function $[2,3]$. However, it is likely that it is Sfx that is responsible for the vast majority of cases of 'true' acute renal failure occurring with co-trimoxazole therapy $[9$, $11-13,32]$.

\section{Trimethoprim, Renal Transplantation and GFR Estimation}

The recent Kidney Disease: Improving Global Outcomes (KDIGO) guidelines strongly recommend that all renal transplant recipients receive daily prophylaxis with co-trimoxazole for at least 6 months for both urinary tract and P. jirovecii infection prevention [52]. Either single strength (80 $\mathrm{mg}$ as trimethoprim) or double strength (160 $\mathrm{mg}$ as trimethoprim) is acceptable. As discussed above, the effect of trimethoprim at $80 \mathrm{mg}$ on serum creatinine concentration is not known, while the higher 160 $\mathrm{mg}$ dose does increase it by approximately $15 \%[27,43]$. This will clearly influence GFR estimation using the Modification of Diet in Renal Disease (MDRD) study equation.

Because the relationship between serum creatinine and GFR is exponential, the effect of trimethoprim on estimated GFR will theoretically be higher in patients with low (or normal) creatinine levels. However, the effect of trimethoprim is especially relevant to higher creatinine levels because it is linked to tubular creatinine secretion, which is GFR dependent. We will thus illustrate the effect of trimethoprim with the following example. A 50-year-old man with a serum creatinine of 1.4 $\mathrm{mg} / \mathrm{dl}$ will have an estimated GFR of $54 \mathrm{ml} / \mathrm{min} / 1.73 \mathrm{~m}^{2}$. A trimethoprim-induced $20 \%$ increase in serum creatinine to $1.68 \mathrm{mg} / \mathrm{dl}$ will reduce the estimated GFR to 43 $\mathrm{ml} / \mathrm{min} / 1.73 \mathrm{~m}^{2}$. These changes in creatinine and estimated GFR could be considered as clinically significant even though the GFR is actually unchanged.

Furthermore, the ability of serum creatinine and estimated GFR based on serum creatinine to accurately detect changes in true GFR in patients not on trimethoprim, which is far more important than their absolute levels, is less than optimal $[53,54]$. GFR estimation poses a particular challenge in kidney transplant recipients $[52,55$, 56]. Trials evaluating the performance of the MDRD study equation and other creatinine-based equations show significant heterogeneity $[55,56]$. Several explanations have been advanced to explain such discrepancies, such as differences in the reference method for GFR measurement, in serum creatinine calibration and in GFR range of the study population [56]. Another hypothesis involves the potential influence of trimethoprim on serum creatinine, with differences between studies in the prevalence and dosage of co-trimoxazole [56]. In two recent studies with a similar distribution of GFR, isotope dilution mass spectrometry (IDMS) traceable serum creatinine concentrations and the same reference method for GFR measurement ( ${ }^{99} \mathrm{Tc}-\mathrm{DTPA}$ clearance) have examined the performance of the MDRD study equation $[57,58]$. In the first, the MDRD study equation underestimated GFR across the entire GFR range. In the second, the same equation systematically overestimated GFR. Twenty percent of the patients in the first study were treated with co-trimoxazole, while none was treated in the second. This could, at least in part, account for the discrepancies between the two trials. The potential role of trimethoprim in the performance of the creatininebased equations is illustrated by another trial published by White et al. [59] in 2007. In this sample of 192 renal transplant recipients, $19 \%$ were treated with co-trimoxazole (160 mg trimethoprim 3 times per week). The accuracy of the MDRD study equation (defined as percentage of patients with an estimated GFR within $30 \%$ of measured GFR) was $80 \%$ in the entire cohort. In the subgroup of patients treated with trimethoprim, the accuracy was decreased to $62 \%$.

\section{Conclusion}

Co-trimoxazole is a recommended and widely used antibiotic for the prevention and treatment of $P$. jirovecii pneumonia and urinary tract infections, especially in transplant recipients $[1-3,52]$. Sfx, and thus co-trimoxazole, may cause an abrupt increase in serum creatinine due to tubulointerstitial toxicity in high or incorrectly adjusted doses. By inhibiting creatinine secretion, trimethoprim can also lead to an elevation in serum creatinine, but this is independent of any changes in GFR. This creatinine 'elevation' impacts on GFR estimation and will lead to the erroneous perception of a more severely impaired kidney function than it actually is.

New GFR biomarkers could be of interest for subjects treated with trimethoprim. For example, plasma cystatin $\mathrm{C}$ is freely filtrated through the glomerulus and is then reabsorbed by renal tubular cells where it is completely metabolized [60]. Thus, trimethoprim should theoretically not influence plasma cystatin $\mathrm{C}$ concentrations.

The effect of trimethoprim on serum creatinine has rarely been studied in recent years. Therefore, more stud- 
ies are necessary to improve our understanding of the potential effect of low-dose $(80 \mathrm{mg})$ trimethoprim on serum creatinine levels. Collaborative trials are also welcome to study the potential effect of this drug on the performance of the creatinine-based equations and to explain discrepancies observed between trials studying the performance of the MDRD study equation in renal transplantation. The effect of trimethoprim on serum creati- nine (and its consequences in terms of GFR estimation) is an old topic, but it would deserve complementary studies.

\section{Disclosure Statement}

We have no conflict of interest to declare.

\section{References}

-1 Brogden RN, Carmine AA, Heel RC, Speight TM, Avery GS: Trimethoprim: a review of its antibacterial activity, pharmacokinetics and therapeutic use in urinary tract infections. Drugs 1982;23:405-430.

2 Cockerill FR, Edson RS: Trimethoprim-sulfamethoxazole. Mayo Clin Proc 1991;66: 1260-1269.

- 3 Masters PA, O’Bryan TA, Zurlo J, Miller DQ, Joshi N: Trimethoprim-sulfamethoxazole revisited. Arch Intern Med 2003;163:402410.

-4 Roth B, Falco EA, Hitchings GH, Bushby SR: 5-Benzyl-2,4-diaminopyrimidines as antibacterial agents. I. Synthesis and antibacterial activity in vitro. J Med Pharm Chem 1962;91:1103-1123.

5 Bach MC, Gold O, Finland M: Absorption and urinary execretion of trimethoprim, sulfamethoxazole, and trimethoprim-sulfamethoxazole: results with single doses in normal young adults and preliminary observations during therapy with trimethoprimsulfamethoxazole. J Infect Dis 1973;128 (suppl):S584-S598.

66 Grose WE, Bodey GP, Loo TL: Clinical pharmacology of intravenously administered trimethoprim-sulfamethoxazole. Antimicrob Agents Chemother 1979;15:447-451.

7 Welling PG, Craig WA, Amidon GL, Kunin CM: Pharmacokinetics of trimethoprim and sulfamethoxazole in normal subjects and in patients with renal failure. J Infect Dis 1973; 128(suppl):556-566.

8 Van Scoy RE, Wilson WR: Antimicrobial agents in adult patients with renal insufficiency: initial dosage and general recommendations. Mayo Clin Proc 1987;62:11421145.

9 Hanley T: Septrim/bactrim-reported adverse reactions, October 14, 1968-April 14, 1969. Postgrad Med J 1969;45(suppl):85.

10 Schofield CB, Masterton G, Moffett M, McGill MI: The treatment of gonorrhoea in women with sulphamethoxazole-trimethoprim. Postgrad Med J 1969;45(suppl):81-86.

11 Kalowski S, Nanra RS, Mathew TH, KincaidSmith P: Deterioration in renal function in association with co-trimoxazole therapy. Lancet 1973;i:394-397.
12 Rudra T, Webb DB, Evans AG: Acute tubular necrosis following co-trimoxazole therapy. Nephron 1989;53:85-86.

13 Bailey RR, Little PJ: Deterioration in renal function in association with co-trimoxazole therapy. Med J Aust 1976;i:914, 916.

14 Chandra M, Chandra P, McVicar M, Susin M, Teichberg S: Rapid onset of co-trimoxazole induced interstitial nephritis. Int J Pediatr Nephrol 1985;6:289-292.

15 Shouval D, Ligumsky M, Ben Ishay D: Effect of co-trimoxazole on normal creatinine clearance. Lancet 1978;i:244-245.

16 Richmond JM, Whitworth JA, Fairley KF, Kincaid-Smith P: Co-trimoxazole nephrotoxicity. Lancet 1979;i:493.

17 Cryst C, Hammar SP: Acute granulomatous interstitial nephritis due to co-trimoxazole. Am J Nephrol 1988;8:483-488.

18 Smith EJ, Light JA, Filo RS, Yum MN: Interstitial nephritis caused by trimethoprimsulfamethoxazole in renal transplant recipients. JAMA 1980;244:360-361.

19 Garvey JP, Brown CM, Chotirmall SH, Dorman AM, Conlon PJ, Walshe JJ: Trimethoprim-sulfamethoxazole induced acute interstitial nephritis in renal allografts; clinical course and outcome. Clin Nephrol 2009; 72:331-336.

20 Pusey CD, Saltissi D, Bloodworth L, Rainford DJ, Christie JL: Drug associated acute interstitial nephritis: clinical and pathological features and the response to high dose steroid therapy. Q J Med 1983;52:194-211.

21 Lehr D: Clinical toxicity of sulfonamides. Ann NY Acad Sci 1957;69:417-447.

22 Tasker PR, MacGregor GA, de Wardener HE: Use of co-trimoxazole in chronic renal failure. Lancet 1975;i:1216-1218.

23 Horn B, Cottier P: Kreatininkonzentration im Serum vor und unter Behandlung mit Trimethoprim-Sulfamethoxazol (Bactrim). Schweiz Med Wochenschr 1974;104:18091812.

24 Caterson RJ, Collett PV, Hood VL, Duggin GG, Horvath JS, Johnson JR, Sampson J, Tiller DJ: Trimethoprim/sulfamethoxazole and renal function in transplant patients. Clin Pharmacol Ther 1978;23:553-557.
25 Berglund F, Killander J, Pompeius R: Effect of trimethoprim-sulfamethoxazole on the renal excretion of creatinine in man. J Urol 1975;114:802-808.

26 Bye A: Letter: drug interference with creatinine assay. Clin Chem 1976;22:283-284.

27 Kastrup J, Petersen P, Bartram R, Hansen JM: The effect of trimethoprim on serum creatinine. Br J Urol 1985;57:265-268.

-28 Berg KJ, Gjellestad A, Nordby G, Rootwelt K, Djoseland O, Fauchald P, Mehl A, Narverud J, Talseth T: Renal effects of trimethoprim in ciclosporin- and azathioprine-treated kidney-allografted patients. Nephron 1989;53: 218-222.

29 Maki DG, Fox BC, Kuntz J, Sollinger HW, Belzer FO: A prospective, randomized, double-blind study of trimethoprim-sulfamethoxazole for prophylaxis of infection in renal transplantation. Side effects of trimethoprim-sulfamethoxazole, interaction with cyclosporine. J Lab Clin Med 1992;119:1124.

30 Odlind B, Hartvig P, Fjellstrom KE, Lindstrom B, Bengtsson S: Steady state pharmacokinetics of trimethoprim $300 \mathrm{mg}$ once daily in healthy volunteers assessed by two independent methods. Eur J Clin Pharmacol 1984;26:393-397.

31 Howards SS: Letter: effect of trimethoprim sulfamethoxazole on the renal excretion of creatinine in man. J Urol 1976;116:134.

32 Trollfors B, Wahl M, Alestig K: Co-trimoxazole, creatinine and renal function. J Infect 1980;2:221-226.

-33 Kainer G, Rosenberg AR: Effect of co-trimoxazole on the glomerular filtration rate of healthy adults. Chemotherapy 1981;27:229232.

-34 Ringden O, Myrenfors P, Klintmalm G, Tyden G, Ost L: Nephrotoxicity by co-trimoxazole and cyclosporin in transplanted patients. Lancet 1984;i:1016-1017.

- 35 Thompson JF, Chalmers DH, Hunnisett AG, Wood RF, Morris PJ: Nephrotoxicity of trimethoprim and cotrimoxazole in renal allograft recipients treated with cyclosporine. Transplantation 1983;36:204-206. 
>36 Nyberg G, Gabel H, Althoff P, Bjork S, Herlitz $\mathrm{H}$, Brynger $\mathrm{H}$ : Adverse effect of trimethoprim on kidney function in renal transplant patients. Lancet 1984;i:394-395.

-37 Maillard N, Mehdi M, Thibaudin L, Berthoux F, Alamartine E, Mariat C: Creatinine-based GFR predicting equations in renal transplantation: reassessing the tubular secretion effect. Nephrol Dial Transplant 2010;25:3076-3082.

-38 Urakami Y, Kimura N, Okuda M, Inui K: Creatinine transport by basolateral organic cation transporter hOCT2 in the human kidney. Pharm Res 2004;21:976-981.

39 Cacini W, Myre SA: Uptake of trimethoprim by renal cortex. Biochem Pharmacol 1985; 34:3483-3488.

40 Lee J, Hollyer R, Rodelas R, Preuss HG: The influence of trimethoprim, sulfamethoxazole, and creatinine on renal organic anion and cation transport in rat kidney tissue. Toxicol Appl Pharmacol 1981;58:184-193.

-41 Shemesh O, Golbetz H, Kriss JP, Myers BD: Limitations of creatinine as a filtration marker in glomerulopathic patients. Kidney Int 1985;28:830-838.

-42 Dijkmans BA, van Hooff JP, de Wolff FA, Mattie H: The effect of co-trimoxazole on serum creatinine. Br J Clin Pharmacol 1981;12: 701-703.

-43 Myre SA, McCann J, First MR, Cluxton RJ Jr: Effect of trimethoprim on serum creatinine in healthy and chronic renal failure volunteers. Ther Drug Monit 1987;9:161-165.

-44 Naderer O, Nafziger AN, Bertino JS Jr: Effects of moderate-dose versus high-dose trimethoprim on serum creatinine and creatinine clearance and adverse reactions. Antimicrob Agents Chemother 1997;41:24662470 .
45 Roy MT, First MR, Myre SA, Cacini W: Effect of co-trimoxazole and sulfamethoxazole on serum creatinine in normal subjects. Ther Drug Monit 1982;4:77-79.

46 Sandberg T, Trollfors B: Effect of trimethoprim on serum creatinine in patients with acute cystitis. J Antimicrob Chemother 1986;17:123-124.

47 Odutola TA, Cameron JS, Sacks S: Effect of co-trimoxazole on plasma creatinine concentrations in renal transplant recipients. Nephrol Dial Transplant 1994;9:1845.

48 Cantaluppi A, Graziani G, Ponticelli C, Grasso S, Meinardi G, Piaia F, Tamassia V: Pharmacokinetic study of the new sulfamethopyrazine-trimethoprim combination (kelfiprim) in renal insufficiency. Eur J Clin Pharmacol 1984;27:345-348.

49 Berglund F: Urinary excretion patterns for substances with simultaneous secretion and reabsorption by active transport. Acta Physiol Scand 1961;52:276-290.

50 Ducharme MP, Smythe M, Strohs G: Druginduced alterations in serum creatinine concentrations. Ann Pharmacother 1993;27: 622-633.

51 Smith GW, Cohen SB: Hyperkalaemia and non-oliguric renal failure associated with trimethoprim. BMJ 1994;308:454.

52 KDIGO clinical practice guideline for the care of kidney transplant recipients: Am J Transplant 2009;9(suppl 3):S1-S155.

53 Delanaye P, Cohen EP: Formula-based estimates of the GFR: equations variable and uncertain. Nephron Clin Pract 2008;110:c48c53.
54 Xie D, Joffe MM, Brunelli SM, Beck G, Chertow GM, Fink JC, Greene T, Hsu CY, Kusek JW, Landis R, Lash J, Levey AS, O’Conner A, Ojo A, Rahman M, Townsend RR, Wang H, Feldman HI: A comparison of change in measured and estimated glomerular filtration rate in patients with nondiabetic kidney disease. Clin J Am Soc Nephrol 2008;3:13321338.

55 Mariat C, Maillard N, Phayphet M, Thibaudin L, Laporte S, Alamartine E, Berthoux F: Estimated glomerular filtration rate as an end point in kidney transplant trial: where do we stand? Nephrol Dial Transplant 2008; 23:33-38

56 White CA, Huang D, Akbari A, Garland J, Knoll GA: Performance of creatinine-based estimates of GFR in kidney transplant recipients: a systematic review. Am J Kidney Dis 2008;51:1005-1015.

57 Poge U, Gerhardt T, Stoffel-Wagner B, Palmedo H, Klehr HU, Sauerbruch T, Woitas RP: Beta-trace protein-based equations for calculation of GFR in renal transplant recipients. Am J Transplant 2008;8:608-615.

58 White CA, Akbari A, Doucette S, Fergusson D, Knoll GA: Estimating glomerular filtration rate in kidney transplantation: is the new chronic kidney disease epidemiology collaboration equation any better? Clin Chem 2010;56:474-477.

59 White C, Akbari A, Hussain N, Dinh L, Filler G, Lepage N, Knoll GA: Chronic kidney disease stage in renal transplantation classification using cystatin $\mathrm{C}$ and creatininebased equations. Nephrol Dial Transplant 2007;22:3013-3020.

60 Seronie-Vivien S, Delanaye P, Pieroni L, Mariat C, Froissart M, Cristol JP: Cystatin C: current position and future prospects. Clin Chem Lab Med 2008;46:1664-1686.

\section{Editorial Comment}

Richard J. Glassock, Laguna Niguel, Calif.

Trimethoprim (in the forms of trimethoprim-Sfx combinations - co-trimoxazole) is one of the most frequently prescribed medications for acute urinary tract and for prophylaxis/treatment of opportunistic infections (P. jirovecii) in immunocompromised patients. The article by Delanaye et al. on the influence of this agent on the estimation of renal function by creatinine-based equations is thus both important and timely. Such equations are commonly used to approximate renal function levels, GFR, for the diagnosis of chronic kidney disease, to evaluate the progression of renal disease (in patients with native kidney disease and in renal allograft recipients), and for determining dosage of water-soluble therapeutic agents cleared by the kidney (mainly by glomeru- 
lar filtration). As shown by Delanaye et al., it is very clear that trimethoprim, even at customary dosages, competitively reduces tubular creatinine secretion and thus leads to a reversible elevation of serum creatinine concentration, and in the steady state to no change in urinary creatinine excretions. Thus GFR estimated by conventional serum creatinine-based formulas (eGFR), such as the eGFR (MDRD) or the Chronic Kidney Disease Epidemiology Collaboration (CKD-EPI) equation as well as the Cockcroft-Gault formula all will be systematically reduced (by about 20-25\%). In addition, values from direct measurement of endogenous creatinine clearance will be similarly reduced. The value for GFR calculated from serum cystatin $\mathrm{C}$ concentration or other noncreatinine markers of GFR will not be affected. The Sfx component of co-trimoxazole has no such effect on creatinine secretion, but, under very uncommon circumstances, can cause direct or immune-mediated kidney injury.

Recognition of these phenomena is crucially important in patients receiving co-trimoxazole, lest errors be made in the interpretation of estimates of renal function that can lead to misdiagnosis and misguided treatment. The contribution of Delanaye et al. reminds us of this important topic, which has been neglected in the recent literature. 